\title{
The Audiobook Market and Its Adaptation to Cultural Changes
}

\author{
Maria Snelling ${ }^{1}$
}

Accepted: 14 September 2021 / Published online: 4 October 2021

(C) The Author(s), under exclusive licence to Springer Science+Business Media, LLC, part of Springer Nature 2021

\begin{abstract}
In recent years, audiobooks have become more popular in the book industry despite the common misconception that listening is less beneficial than reading a physical book. Marketers used technology as a channel to target consumers and convince them to listen to the audiobook for multitasking and productivity purposes. Through transmedia, author branding and influence culture, the audiobook market has proven its elasticity in response to the coronavirus pandemic. It was assumed that audiobooks would not perform as planned in 2020 since COVID-19 seized most travel; therefore, consumers stopped listening to audiobooks as part of their travel routine. Instead, digital audiobooks continued their upgrowth trajectory and thrived as a method of relaxation during the pandemic.
\end{abstract}

Keywords Audiobooks · Marketing · COVID-19 $\cdot$ Publishing $\cdot$ Smartphone · Technology $\cdot$ Transmedia

\section{Introduction}

Audiobooks have taken several forms over the years, most notably from a physical product purchased at a store to a digital downloadable code on your smartphone, but have never been as favored as the hardcover format. Since print books were much easier and less expensive to create at the time audiobooks were recorded for the phonograph in the late 1800 s, the audiobook industry was not as successful as the print books due to availability and convenience. ${ }^{1}$ Yet, there's a misconception that the hardcover is not only superior but that audiobooks are cheating the print book. Some feel they don't retain as much information when they listen than when they read; others feel that listening is more pleasurable, especially if it is a common practice. ${ }^{2}$

\footnotetext{
${ }^{1}$ Rubery [29].

${ }^{2}$ Hutton [15].

Maria Snelling

snellingmaria@gmail.com

1 New York, NY 10016, USA

记 Springer
} 
Because some consumers fully believe these misguided ideas, audio publishers face extra obstacles when marketing their titles. In fact, it was believed for audiobooks to be successful, they have to not only create as much revenue as the print book but have to surpass the entertainment value of the print book in order to be valued. ${ }^{3}$ People, in general, are hesitant to change any habit, especially their reading style, which is why target marketing is vital to a book's success; the marketers find unique ways to attract consumers and convince them to listen to the audiobook rather than read the print version. ${ }^{4}$ In 2010 , digital and physical audiobooks shared $1.96 \%$ of total trade revenue $;^{5}$ whereas in 2020 , digital audiobooks alone contributed $8.3 \%$ of total trade revenue in the book industry. ${ }^{6}$ Although audiobook sales continue to rise, they do not yet bring in the same revenue of print books; all forms of print books bring in over three-fourths of US trade sales every year. ${ }^{7}$ Consequently, the audiobook format has increased in popularity but is still not seen as the same value as print books due to the popularity and revenue success.

Audiobooks, podcasts and other forms of listening-based entertainment have been found to be more popular, especially during the coronavirus pandemic, as smartphone technology becomes more innovative. ${ }^{8}$ Digital audiobooks can be downloaded to your smartphone in minutes and are convenient on-the-go, especially during one's daily commute. In recent times, COVID-19 has greatly affected sales in the publishing industry beginning with the US shutdown in March 2020. The audiobook sales, among plenty of other retail businesses, dropped during the early months in the pandemic since many consumers were not commuting every day and therefore not listening. ${ }^{9}$ Before COVID-19, a study from the Audio Publishers Association (APA) showed $50 \%$ or more listeners ages twelve and up listened to an audiobook in 2019; this was the highest percentage the APA had ever seen. ${ }^{10}$ It's evident that regardless of COVID-19, audiobook listeners remained loyal to the auditory platform; in fact, the community seemed to have grown during the pandemic as $32 \%$ of listeners claimed they listened to more audiobooks in the past year and 50\% reported they listened to the same amount. Compared to 2020, only $29 \%$ of listeners stated they listened to more audiobooks in the year and 52\% said they listened to the same amount. $^{11}$

At a glance, audiobooks and podcasts began to appeal more to commuters in the past decade, emphasizing that audiobooks are accessible and versatile and can increase productivity. ${ }^{12}$ Audiobooks and podcasts allow listeners more freedom as

\footnotetext{
3 Rubery [29].

4 Roche [28].

5 Soares [31].

6 Anderson [2].

7 Stewart et al. [32].

8 Edison Research [8].

9 Edison Research [9].

10 Audio Publishers Association [5].

11 Edison Research [9].

12 Edison Research [8].
} 
a hands-free activity and have recently been used for pleasure and relaxation. ${ }^{13}$ In the current unprecedented times of COVID-19 and in past political and social movements, the publishing industry has adapted to cultural change through content, format and strategy, just as it had in the past with major technological advancements. By switching forms from a physical compact disc (CD) to digital downloads, the audiobook market is now thriving on the digital platform. Strategizing innovative marketing techniques for audiobooks has been one of marketers' greatest struggles, which creates a bigger challenge as consumers adjust to a remote lifestyle. In response to commuters', educators' and consumers' need for screen time reduction, audio publishers are utilizing COVID-19's push for a virtual world by marketing and reaching their audiences online. Looking ahead, digital audiobooks will continue to increase in popularity, especially as smartphone and smarthome technology becomes more advanced.

\section{Audiobook Unique Marketing Tactics}

Most often, audiobooks are not the top-selling format for a given title but rather the hardcover edition. As audiobooks shifted from physical products to digital downloads, publishers assumed the audiobook would sell $10 \%$ of the net units sold by the print book. In the past few years, that guide is no longer useful since some publishers find their audiobooks are the lead format, meaning the audiobook has more sales than the hardcover or ebook editions. ${ }^{14}$ While there's not just one answer to why audiobooks are sometimes the lead format, publishers analyzed the author platform and genre of the books to determine why titles succeed on audio and some do not; this creates additional challenges for the marketing team. Because the audio department is treated as a separate division (as opposed to an audio-specific team for each imprint) at most Big Five publishers, the audiobook edition is promoted by its own marketing and publicity teams. While the print, ebook and audio teams often collaborate on major campaigns, the audiobook is not always as successful as the print edition due to the higher demand by readers than listeners. In that case, the audio team struggles with promoting their titles; their target audience narrows from all book consumers to solely listeners within that targeted community. ${ }^{15}$ Often, the audio marketing team homes in on unique tactics to persuade consumers to listen or magnify how this title is appealing as an audiobook.

One of the biggest challenges audio marketing teams have faced is ensuring their marketing efforts are supporting the audiobook format, specifically. ${ }^{16}$ By searching for spaces where long-time listeners often enjoy audiobooks, publishers have promoted their titles in these locations to give the incentive to listen on that platform.

\footnotetext{
13 Zable Fisher [34].

14 Roche (President and Publisher, Macmillan Audio) in discussion with the author [28].

15 Mary Beth Roche (President and Publisher, Macmillan Audio) in discussion with the author [28].

16 Mary Beth Roche (President and Publisher, Macmillan Audio) in discussion with the author [28].
} 
In 2020, the APA reported that cars remained the top location for listening to audiobooks. ${ }^{17}$ For years, Macmillan implemented several "innovative partnerships" with car rental companies. With every rental, the consumer would receive either an excerpt or the full audiobook depending on the promotion, which planted the idea in the consumer's head to listen to the audiobook while driving. Furthermore, Macmillan extended their campaign to car washes, handing out free downloadable codes for early listens of a chapter. These plans were executed and deemed successful as the idea of listening while driving was introduced to new consumers who had never before thought to enjoy books audibly or while traveling, further promoting the incentive that was originally planted by the marketing team proved successful in sales. $^{18}$

\section{Targeting the Audience}

The marketing and publicity teams play a vital role in the success of selling consumer goods, but they face obstacles when it comes to working in the publishing field. One of the key steps in creating a successful marketing campaign is to identify who the audience is, why they want to listen and in what ways will they best see or hear information on the audiobook. ${ }^{19}$ In recent years, the main reason people listen to audiobooks are for entertainment and brain stimulation, according to a 2020 study. ${ }^{20}$ In the audio industry, the listening community is loyal to the format, making targeting listeners on audio-based platforms, such as podcasts and radio stations, easily accessible. Many podcast listeners are more likely to listen to an audiobook than to read a physical book because they are more familiar with audio-centered platforms. $^{21}$

In addition to podcast listeners, book clubs have been targeted by audiobook marketers to switch their monthly read to a monthly listen. For the campaign of Daisy Goodwin's The American Heiress, ${ }^{22}$ marketers targeted book clubs in every state, gathering a list of several hundred participating book clubs to send early audio files for early listening promotion. After listening to the early excerpts, the book clubs who chose to participate willingly swapped their monthly read to The American Heiress audiobook in honor of June being the month of publication and National Audiobook Month. ${ }^{23}$ This enforced the unique tactic in the marketing team's plans: to introduce the idea of listening to the audiobook to consumers. The buzz surrounding the book clubs using an audiobook as their monthly pick for the first time leaked into other trade audiences, further convincing consumers to purchase the audiobook

\footnotetext{
17 Audio Publishers Association [3].

18 Mary Beth Roche (President and Publisher, Macmillan Audio) in discussion with the author [28].

19 Mary Beth Roche (President and Publisher, Macmillan Audio) in discussion with the author [28].

20 Kozlowski [17].

21 Edison Research [9].

22 Goodwin [11].

23 Mary Beth Roche (President and Publisher, Macmillan Audio) in discussion with the author [28].
} 
rather than the print book. ${ }^{24}$ Even today, there are book clubs that are dedicated only to audiobooks; the number of audiobook clubs have increased during the coronavirus pandemic as consumers looked for alternate ways to unplug yet stay involved with friends. ${ }^{25}$

In addition to reaching audiences in new locations, marketers look to target consumers by promoting its versatility and productivity benefits. Since listening is a hands-free activity, many take advantage of this and use headphones while traveling or completing household chores, something audiobook marketers have been trying to carry out in their campaigns when reaching new audiences. In a Publishers Weekly article from 2005, audiobook marketing was suggested to target commuters and multitaskers, since typical consumers were too busy to sit down and visually read a book. It was recommended to promote audiobooks as time-saving entertainment alongside the print book. ${ }^{26}$ Even today, audiobooks are often advertised as a way to enjoy a book while performing other tasks. ${ }^{27}$ By emphasizing the productivity aspect, publishers can tap into niche communities to listen rather than read. With an extensive background in book publicity, Mary Beth Roche, President and Publisher of Macmillan Audio, explained the key to audiobook marketing is "not so much specifically promoting a particular title but explaining to consumers and showing to consumers how they might include audio as a multitasking tool while doing other things they love." ${ }^{28}$ When targeting consumers online, marketers look to reach, captivate and maintain that audience on the right platform and feed consumers their product advertisements. ${ }^{29}$

\section{Transmedia and Platform}

As backlist titles across all publishers continue to make up about two-thirds of industry-wide revenue, this creates greater challenges for debut authors to become acquired since they often don't have as strong a platform as an already established author. ${ }^{30}$ In response, new authors are scrounging to create this engagement with their followers through blogs, newsletters, and other forms of media while earning their book deal. Collectively, the author interacting with consumers and presenting their artwork or knowledge through these different channels is an example of social branding [14]. In 2021, social media and technology, in general, are prominent features in our society. With the recent rise of the app TikTok, publishers are now attempting to promote through the hashtag booktok but are just starting to take off while other retail businesses on the platform, such as the beauty industry, have already seen success from TikTok influencers. The New York Times published

\footnotetext{
24 Mary Beth Roche (President and Publisher, Macmillan Audio) in discussion with the author [28].

25 Mary Beth Roche (President and Publisher, Macmillan Audio) in discussion with the author [28].

26 Hutton [15].

27 Rubery [29].

28 Mary Beth Roche (President and Publisher, Macmillan Audio) in discussion with the author [28].

29 Hunt et al. [14].

30 Nawotka [25].
} 
several articles in the spring of 2021 that named TikTok and other social media influencers as the newest way to market to the Gen-Z and Millennial generations who define consumer culture. ${ }^{31}$ With the influx of social media influencers, TikTok launched the rise of backlist sales, pushing titles from 2014 back on the New York Times best sellers list. ${ }^{32}$ The TikTok community organically created this publicity surrounding backlist titles, which still benefited publishers. Now, some publishers are searching for methods to introduce frontlist titles on TikTok naturally, without disrupting how the \#booktok community currently operates. This has been a challenge since publishers are forced to adapt to a different platform with a younger audience, after they've been comfortable with advertising on other social media accounts like Facebook, Instagram, Reddit and Twitter.

When authors and narrators have large enough followings on social media, they can host Facebook Live, Instagram Live or Reddit Ask Me Anything (AMA) events with each other and special guests, which allows consumers to better understand the creators of the audiobook. ${ }^{33}$ Live virtual events through social media often work best when there is a higher following and engagement of the participants because their community will attend the event. ${ }^{34}$ Creating a social brand for authors can be a key feature to their success because they can build that engagement on social media and within their community. If there's no voice from the author shown in the content on different mediums, then there's no guide for the audience to follow across the different transmedia, ultimately losing interest quickly. ${ }^{35}$ Social branding for authors can be directly related to transmedia, or the idea to create and tell a story across different channels, ${ }^{36}$ since authors are expanding their platform to construct a strong base for their author brand.

Since audiobooks are mainly listened to digitally today, audio publishers sometimes look for audio-specific elements from the author's platform, such as a podcast or radio show host, before acquiring that title. ${ }^{37}$ A successful platform for audiobook leverage is the My Favorite Murder podcast hosted by Karen Kilgariff and Georgia Hardstark. ${ }^{38}$ Their podcast audience was engaged and enthused because Kilgariff and Hardstark took the true crime element that kept listeners hooked and incorporated some truth about the duo's personal lives to produce the provocative tell-all book, Stay Sexy \& Don't Get Murdered. ${ }^{39}$ As a result, the My Favorite Murder audience was accustomed to hearing true crime stories through Kilgariff and Hardstark's voices, which made the audiobook edition, narrated by the authors, "disproportionately successful" to the print book. ${ }^{40}$ Because the popularity of their podcast

\footnotetext{
31 Grigoriadis [10].

32 Harris [12].

33 Polson [27].

34 Mary Beth Roche (President and Publisher, Macmillan Audio) in discussion with the author [28].

35 Hunt et al. [14].

36 Levitz [23].

37 Mary Beth, Roche (President and Publisher, Macmillan Audio) in discussion with the author [28].

38 Kilgariff and Hardstark [19], produced by Exactly Right, podcast, https://myfavoritemurder.com/.

39 Kilgariff and Hardstark [20].

40 Mary Beth, Roche (President and Publisher, Macmillan Audio) in discussion with the author [28].
} 
garnered so much publicity for the book, Kilgariff and Hardstark were able to have actor Paul Giamatti, long-time listener and fan of the My Favorite Murder duo, on the program. Giamatti's cameo appearance alone increased the buzz surrounding the audiobook even further. Similar to book readers, the podcast listeners are more likely to choose to enjoy the book in the format they are more familiar with, which further supports the audio marketing team's decision to target the My Favorite Murder fans. By targeting podcast listeners, publishers are more likely to convince the consumer to listen to an audiobook chapter instead of a podcast episode. While the narration is a key feature for all audiobooks, the well-established platform and the ability to target listeners through the podcast was instrumental to Stay Sexy and Don't Get Murdered's success. ${ }^{41}$

While the book publishing industry does not necessarily create brands through publishers, brands are created by authors, like Kristin Hannah, Stephen King, Elizabeth Gilbert and Frank Herbert, where their work has landed across different mediums: books, television shows, movies, book clubs, writing communities, social media fan clubs and more. The idea of incorporating author branding with transmedia allows access to different fanbases on different platforms, ultimately generating more revenue and publicity for the author and the publisher. ${ }^{42}$ Especially in the advanced technological era of the 2020s, spreading the author's name and work across social media platforms and to other forms of entertainment create that recognizable author brand.

\section{Technology as a Channel for Listeners}

The rise in the digital era has played a large role in today's audiobook market, reaching a wider range of people and persuading them to become a listener. ${ }^{43}$ Because about $95 \%$ of the industry is currently consumed through digital audiobook downloads versus physical CDs, mobile device consumption correlates with the format change; as consumers converted to smartphone technology, digital audiobooks grew in popularity over physical products because the consumers' focus was now on a digital channel. ${ }^{44}$ In 2020, CDs and physical products contributed less than $5 \%$ to the audiobook industry and were far more expensive to produce, ${ }^{45}$ whereas the digital product has clearly dominated sales and been favored by publishers since the 2010s. In fact, physical products in 2010 (cassette tapes, pre-recorded players and CDs) generated $64 \%$ of revenue for the audio industry. ${ }^{46}$ At the time, digital audiobooks were just being introduced and were not as attainable for listening since smartphone

\footnotetext{
41 Mary Beth Roche (President and Publisher, Macmillan Audio) in discussion with the author [28].

42 Levitz [23].

43 "Audiobooks market size, trends analysis report by genre, by preferred device (smartphones, laptops and tablets, personal digital assistants), by distribution channel, by target audience, by region, and segment forecasts, 2020-2027," [6].

44 Anderson [2].

45 Edison Research [9].

46 Lewis and Clark [22].
} 
and smarthome technology was not as advanced as it is today. Soon after, digital audiobooks became the lead format in the industry because they did not have plant costs for physical production nor did they have a return rate, which made them more profitable than any physical product. ${ }^{47}$

Correspondingly, the average audiobook listener consumed 8.1 titles in 2020, an increase from the 6.8 titles in $2019 .{ }^{48}$ The 2021 APA consumer survey noted that consumers on average listened to 7.6 titles from March 2020 to March 2021. Although the number of audiobooks consumed decreased in the latest survey, the APA concluded the listening community did not decrease in size, but rather some audiobook listeners reverted to podcast or music streaming options during the first year of the pandemic.

\section{Cars, Smarthomes and Smartphones}

For the past several years, the top place to listen to audiobooks was in the car. ${ }^{49}$ Since the United States and China are the two countries with longest average commute times, it is no surprise they both dominate the global audiobook market ${ }^{50}$; this supports the connection commuters have with listening to audiobooks while they travel. In a 2019 survey conducted by Edison Research and Triton Digital, 74\% of listeners reported listening to audiobooks in their cars as the most popular listening location, surpassing listening in homes at $68 \% .{ }^{51}$ In a survey conducted by Infinite Dial, $19 \%$ of Americans ages twelve and up were consistently driving and riding in cars with advanced in-dash entertainment and speaker systems that offered better smartphone syncing tools. Of these respondents, $62 \%$ of them have listened to an audiobook using these advanced tech systems in their car. ${ }^{52}$ Waze, a driving navigation app for your smartphone, incorporated Audible and other audio players such as Pandora and Spotify to its app during the pandemic. While the Audible app is playing, Waze syncs with the audio players and will simultaneously alert the consumer of direction and oncoming danger. ${ }^{53}$ This was a helpful tool for drivers while the majority of their listening time was spent in the car. By 2021, COVID-19 forced stay-at-home measures which greatly decreased commute times and therefore, listening time spent in the car. Furthermore, only $64 \%$ of listeners reported they consumed an audiobook in the car during the pandemic. As a result, audiobooks were found to be listened most often at home by $55 \%$ of consumers, which is a $12 \%$ increase from the year prior. The APA concluded that consumers are listening more

\footnotetext{
47 Mary Beth Roche (President and Publisher, Macmillan Audio) in discussion with the author [28].

48 Audio Publishers Association [3].

49 Audio Publishers Association [3].

50 Stewart et al. [32].

51 Edison Research [8].

52 Audio Publishers Association [5].

53 Moon [24].
} 
at home and through mobile devices rather than in the car during the first year of the pandemic. $^{54}$

Similar to the advancements cars are manufactured with now, smart home technology offers easy ways to play audiobooks aloud in a given room, while either sitting with friends and family, completing chores or cooking. For example, some smarthome devices can only play audiobooks from certain accounts like Amazon's Echo and Audible. Because both devices are owned by Amazon, they work in-sync and allow listeners to enjoy them seamlessly. As of summer 2021, not all audiobook distributors are compatible with all smarthome streaming devices, which adds to Amazon's success as the top bookseller. ${ }^{55}$ In addition to audiobooks playing in cars and in smarthome technology, audiobooks are often played through smartphones, which have become a major contributor to the rise of digital audiobooks.

With smartphone technology becoming more innovative each day, consumers are engaging more with their mobile devices on applications for email, shopping, entertainment, social media and more. During the pandemic, consumers longed for an "escape" from screens ${ }^{56}$ playing audiobooks from mobile devices allowed consumers to listen while doing other things like folding laundry, walking the dog or just relaxing. ${ }^{57}$ Recently, audio publishers have been more invested in producing their titles as digital downloads to be compatible for mobile devices, since that is how consumers are mainly listening to their audiobooks. ${ }^{58}$

\section{Educators and Librarians}

In the first year of COVID-19, audiobooks were listened to by $14 \%$ more children under the age of eighteen than they had been the year prior. ${ }^{59}$ Since parents were working from home and caring for their children simultaneously, parents purchased more audiobooks than print books for educational purposes, in efforts to entertain children while reducing their time on screens at home. ${ }^{60}$ In fact, $73 \%$ of parents in 2021 reported they were more interested in purchasing audiobooks for their children, which is a $4 \%$ increase than in $2020 .{ }^{61}$ The increase in children's listening is partly owed to educators and librarians. Because children were not in the classroom, visually focusing on a computer screen for eight hours in a day was challenging for

\footnotetext{
54 Edison Research [9].

55 "Audiobooks market size, share and trends analysis report by genre, by preferred device (smartphones, laptops and tablets, personal digital assistants), by distribution channel, by target audience, by region, and segment forecasts, 2020-2027." [6].

56 Edison Research [9].

57 Lamb [21].

58 Edison Research [9].

59 Edison Research [9].

60 "Audiobooks market size, share and trends analysis report by genre, by preferred device (smartphones, laptops and tablets, personal digital assistants), by distribution channel, by target audience, by region, and segment forecasts, 2020-2027." [6].

61 Edison Research [9].
} 
developing minds. In response, some schools attempted to incorporate more audiobooks to correspond with lessons. ${ }^{62}$

Listening is a different experience than visually reading, which can help children develop their learning comprehension with practice. ${ }^{63}$ In a Time magazine article, several studies were recorded in classrooms on listening versus reading comprehension. The students who listened to a podcast performed, on average, $28 \%$ lower on the comprehension quiz than students who read the transcript of that podcast. Although this study did not favor listening initially, it was concluded that with more practice, listeners can train their brains to retain information auditorily. ${ }^{64}$ This does not necessarily mean visually reading is better comprehendible than auditorily reading, but rather there hasn't been as much focus on auditory reading in the classroom. After much of 2020 and 2021 classes took place remotely, the education system is actively working to find alternative methods for students to learn and engage online. By listening to audiobooks alone, children can learn more sophisticated vocabulary, improve pronunciation and listening skills, foster narrative structure based on the tone of the reader and more. ${ }^{65}$ Some students who struggle with reading comprehension have difficulty in focusing on a page with written text. Listening to audiobooks may be more appealing to them, especially if they are stronger auditory learners than visual learners. ${ }^{66}$ In addition to auditorily learning, the APA studied audiobook consumption and listening speed; they reported $40 \%$ of all audiobook listeners claimed listening helped them consume more titles and at a quicker pace. Of those who read print books and listened digitally, $56 \%$ prefered to listen to their audiobooks due to convenience and pace. ${ }^{67}$ Especially during hybrid and remote learning situations due to the pandemic, audiobooks have helped students of all ages learn through different senses and have been a key tool to finding solace. ${ }^{68}$

\section{Responding to COVID-19}

When the COVID-19 pandemic hit the United States in early 2020, the country implemented stay-at-home restrictions for the majority of the spring season and on. As a result, major retail businesses, especially independent bookstores, suffered due to the lack of in-store traffic. The Strand, one of New York's famous bookstores, called for help as they were nearing major financial trouble due to online bookseller Amazon's tremendous success during the pandemic. ${ }^{69}$ Amazon dominated the

\footnotetext{
${ }^{62}$ Lamb [21].

63 Heid [13].

64 Heid [13].

65 "Audiobooks market size, share and trends analysis report by genre, by preferred device (smartphones, laptops and tablets, personal digital assistants), by distribution channel, by target audience, by region, and segment forecasts, 2020-2027." [6].

${ }^{66}$ Lamb [21].

67 Audio Publishers Association [5].

68 Audio Publishers Association [4].

69 Pengelly [26].
} 
online shopping business as they were responsible for the majority of consumer purchases during the pandemic, ultimately hurting independent bookstores. ${ }^{70}$ With the coronavirus and major financial strains spreading through the printing and shipping companies, ${ }^{71}$ publishers made executive decisions to postpone releasing titles to the fall of 2020 or even into 2021 instead of that spring/summer season. ${ }^{72}$ Publishers strategically planned which season they were moving those titles to, keeping in mind to have enough time to execute marketing campaigns and not to compete with other titles in similar genres publishing at the same time. ${ }^{73}$ Thus, publishers were hesitant to release books in late October and November due to the 2020 Presidential election that consumed all major media outlets. ${ }^{74}$ Often, many cultural or political events, such as the aforementioned election, take precedence in the media than a new book release (unless there is a connection to the affair); this succession of cultural events explains why publishers were reluctant to push titles to the fall season since consumers would be distracted by what was covered by the media. As often forgotten, publishing is, indeed, a business; publishers were hesitant to take those financial risks during the fall 2020, knowing the weight this election held in the US. ${ }^{75}$

The audiobook industry had more elasticity during the first year of the pandemic than other retail businesses because much of their business is conducted online to begin with. Even when the pandemic delayed shipments across the country, audio publishers were able to send reviewers advanced listening copies (ALCs) digitally rather than mailing physical CDs for early listens. ${ }^{76}$ The technological advancements greatly benefited the audio industry as they were able to overcome the financial loss in mid-2020 where other businesses could not. A study conducted by Deloitte predicted that digital audiobook sales were to continue increasing, bringing in $\$ 1.5$ billion in $2020 .{ }^{77}$ In fact, for the ninth straight year of double-digit growth, the audiobook revenue grew by $12 \%$ in 2020 to $\$ 1.3$ billion. ${ }^{78}$ Considering the drastic lifestyle change caused by the pandemic, the loss of commuter listening to the gain of at-home listening correlates with the audiobook industry's resilience to cultural changes by nearly achieving Deloitte's 2020 predicted revenue.

\section{Finding Pleasure in Listening}

According to a study conducted by Edison Research, an estimated $45 \%$ of the US population listened to an audiobook in 2020, down from the $50 \%$ that listened in 2019. The most recent consumer survey by the APA recorded $46 \%$ of consumers

\footnotetext{
70 Italie [16].

71 Alter [1].

72 Mary Beth Roche (President and Publisher, Macmillan Audio) in discussion with the author [28].

73 Mary Beth Roche (President and Publisher, Macmillan Audio) in discussion with the author [28].

74 Alter [1].

75 Mary Beth Roche (President and Publisher, Macmillan Audio) in discussion with the author [28].

76 Mary Beth Roche (President and Publisher, Macmillan Audio) in discussion with the author [28].

77 Stewart et al. [32].

78 Audio Publishers Association [4].
} 
listened to an audiobook from March 2020 to March $2021 .^{79}$ As previously stated, popularity in audio-centered platforms contributes to more listeners who are likely to choose an audiobook over a print book. Despite the drop in number of audiobook listeners compared from two years ago, online audio (podcasts, radio shows, music and audiobooks) has become more popular than ever before. ${ }^{80}$ This research combined with the stress and anxiety caused by the coronavirus pandemic explains why consumers searched for audiobooks that were pleasurable and less emotionally stimulating. ${ }^{81}$ As stated in The Washington Post, "during the pandemic, something as low-tech as hearing other humans' voices can fulfill a different kind of need for people who are isolated, all without the anxiety or pressure of having to be seen or even talking back." 82 In comparison to podcasts, $73 \%$ of listeners reported they preferred audiobooks as a way to relax. Listeners found audiobooks more pleasurable than reading visually due to the constant eye strain from excessive screen time. ${ }^{83}$

Some found listening to audiobooks during quarantine was more comforting and satisfying than reading a physical book. ${ }^{84}$ In fact, reading was found to be a challenge, when pre-COVID it was a pleasure; some used listening as a self-soothing exercise. ${ }^{85}$ In fact, audiobooks offer brain stimulation and relaxation, which is one of the main reasons the statistically-proven most stressed and anxious generation, young working professionals, enjoy listening to audiobooks. ${ }^{86}$ Moreover, COVID-19 has forced people to switch to digital book options, transitioning some print readers to e-readers and listeners. ${ }^{87}$ Listening to an audiobook is screen-free, which offered some solace during the pandemic when the majority of consumers are working and studying virtually. ${ }^{88}$ More time is being spent on screens now than ever, that it can be hard to focus visually on text; whereas audiobooks can be an alternative form of focusing, while still entertaining and educating people. ${ }^{89}$ As several vaccinations have been circulating the US as of early 2021, we have seen travel for pleasure and commuting to work resumed for some in the summer, further increasing consumer listening; this combined with the new listeners who found comfort in audiobooks during the pandemic will expand the audiobook market, raise the digital sales and boost competition with the book's alternate formats.

\footnotetext{
79 Edison Research [8].

80 Edison Research [8].

81 Edison Research [9].

82 Kelly [18].

83 Edison Research [9].

84 "Consumer Purchases Reveal Desire for Stress Relief and Self-Care While at Home, Reports NPD," [7].

85 Sackton [30].

86 "Audiobooks market size, share and trends analysis report by genre, by preferred device (smartphones, laptops and tablets, personal digital assistants), by distribution channel, by target audience, by region, and segment forecasts, 2020-2027." [6].

87 Kozlowski [17].

88 "Audiobooks market size, share and trends analysis report by genre, by preferred device (smartphones, laptops and tablets, personal digital assistants), by distribution channel, by target audience, by region, and segment forecasts, 2020-2027." [6].

${ }^{89}$ Sackton [30].
} 
Quickly after the start of the US lockdown, marketers had to find unique language to target their audiences without seeming insensitive to the stress caused by the pandemic. In the spring of 2020, many consumers expressed they felt a bleak, dampening mood, which affected their title selections. ${ }^{90}$ Consequently, Macmillan Audio's marketing and publicity teams were mindful of their language and strategies when posting on social media and reaching out to authors and reviewers. Moreover, digital distributors reported that listeners were selecting titles that were more optimistic and distracting from the current global situation. Roche was intrigued by the feedback from various distributors, since they asked for title lists from specific genres, such as humor and contemporary romances, for promotional purposes. Distributors typically preferred to promote a wide range of genres so they could reach as many communities as possible, but the emotional strain from COVID-19 led consumers to listen to more frivolous audiobooks. ${ }^{91}$ By 2021, the APA reported Mysteries/Thrillers/ Suspense as the most popular audiobook genre. In addition, more consumers were interested in listening to Romance, Self-Help and Business genres. ${ }^{92}$ While Roche recalled the gloomy tone that seemed to have been cast over the country and affected how people listened and advertised audiobooks; an unavoidable challenge was to find the correct tone while promoting the title that would distract consumers from the devastating news on all media outlets while still being sensitive to the pandemic. The goal of the marketing team during these early days was to target the audience with highly entertaining titles without seeming too callous. ${ }^{93}$

\section{Conclusion}

Before the COVID-19 pandemic, audiobooks were reporting double-digit growth in revenue year over year since 2012. Although the pandemic hurt many retail businesses, in a way, audiobooks were seen as an escape from reality and helped consumers find comfort in staying home. ${ }^{94}$ Looking ahead, audiobooks will continue to become a more prominent format in the publishing industry, especially after the influx of use during the first year of the pandemic. Furthermore, the average consumer purchased more products online than in-store during the pandemic than ever before. Since digital audiobooks are easily attainable and can be purchased from a smartphone, the audio publishing industry should continue to increase with the advancement of mobile device consumption, despite the uncertain future of worklife and COVID-19.

As mentioned before, publishers were forced to delay the publication of some titles during the coronavirus pandemic due to printing issues. Because publishers were not releasing as many frontlist titles as they had expected during their spring/summer

\footnotetext{
90 Anderson [2].

91 Mary Beth Roche (President and Publisher, Macmillan Audio) in discussion with the author [28].

92 Audio Publishers Association [4].

93 Mary Beth Roche (President and Publisher, Macmillan Audio) in discussion with the author [28].

94 Vasishta [33].
} 
2020 season, consumers had no other choice but to turn to backlist titles, which were organically promoted through TikTok. The app's popularity redefined social branding as influencers drove sales in various retail brands during the pandemic. Now, publishers are attempting to promote on TikTok because of its audio element, but they have not found that special connection they can make with the community as they have on other social media platforms. Similar to other audio-visual platforms, influencers have trouble showcasing the audiobook as a digital product. ${ }^{95}$

Today we see how the digital audiobook industry has become more popular among consumers, especially with smartphone and smarthome technology. Moving ahead, we can assume that digital books (both audiobook downloads and ebooks) will continue to rise in alignment with the advancement of mobile device technology. While hardcover books will never lose their popularity, it can be predicted that digital audiobooks will continue on their upward, double-digit growth trajectory ${ }^{96}$ even as the future of work and school life is uncertain. Now that audiobooks are primarily digital, the industry's ability to adapt to and surpass the challenges presented by COVID-19 further proves its elasticity to cultural changes.

\section{References}

1. Alter A. Printer jam: serious supply issues disrupt the book industry's fall season. The New York Times, August 27, 2020. https://www.nytimes.com/2020/08/27/books/printing-companies-backlogbook-publishing.html.

2. Anderson P. AAP StatShot: US trade book sales Up 9.7 percent for 2020. Publishing Perspectives, February 25, 2021. https://publishingperspectives.com/2021/02/aap-statshot-sees-us-trade-booksales-up-9-7-percent-for-2020-covid19/.

3. Audio Publishers Association. Audiobooks continue their market rise with $16 \%$ growth in sales. Audio Publishers Association, June 18, 2020. https://www.audiopub.org/uploads/pdf/2020-Consu mer-Survey-and-2019-Sales-Survey-Press-Release-FINAL.pdf.

4. Audio Publishers Association. Audiobook listening remains strong in 2020 as publishers report ninth straight year of double-digit growth. Audio Publishers Association, June 1, 2021. https:// cdn.ymaws.com/audiopub.site-ym.com/resource/collection/63CA49A7-1450-449A-A718-8ACCA 7250FF9/2021_Consumer_\&_2020_Sales_Surveys_Press_Release.pdf.

5. Audio Publishers Association. New survey shows 50\% of Americans have listened to an audiobook. Audio Publishers Association, April 24, 2019. https://www.audiopub.org/uploads/pdf/ConsumerSurvey-Press-Release-2019-FINAL.pdf.

6. "Audiobooks market size, share and trends analysis report by genre, by preferred device (smartphones, laptops and tablets, personal digital assistants), by distribution channel, by target audience, by region, and segment forecasts, 2020-2027." Grand View Research, June 2020. https://www. grandviewresearch.com/industry-analysis/audiobooks-market.

7. "Consumer purchases reveal desire for stress relief and self-care while at home, reports NPD." NPD, The NPD Group, December 23, 2020. https://www.npd.com/wps/portal/npd/us/news/press-releases/ 2020/consumer-purchases-reveal-desire-for-stress-relief-and-self-care-while-at-home--reports-npd/.

8. Edison Research. The infinite dial 2021. Edison Research, March 11, 2021. https://www.edisonrese arch.com/the-infinite-dial-2021-2/.

9. Edison Research. Audio publishers association audiobooks survey. Audio Publishers Association, April 22, 2021.

\footnotetext{
95 Mary Beth Roche (President and Publisher, Macmillan Audio) in discussion with the author [28].

96 Audio Publishers Association [4].
} 
10. Grigoriadis V. The beauty of 78.5 million followers. The New York Times Magazine, March 23, 2021. https://www.nytimes.com/2021/03/23/magazine/addison-rae-beauty-industry.html.

11. Goodwin D. The American heiress. New York: Macmillan Publishers; 2012.

12. Harris EA. How crying on tiktok sells books. The New York Times, March 20, 2021. https://www. nytimes.com/2021/03/20/books/booktok-tiktok-video.html.

13. Heid M. Are audiobooks as good for you as reading? Here's what experts say. Time, September 6, 2018. https://time.com/5388681/audiobooks-reading-books/.

14. Hunt T, Pacheco C, Appugliesi A. Creating a social brand. Produced by Truly Inc. Anatomy of a Strategy. September 16, 2018. Podcast, MP3 audio. https://pod.link/1381161116/episode/f4dc3 $800 \mathrm{bbd} 9 \mathrm{f} 44 \mathrm{da} 81 \mathrm{cf} 2 \mathrm{f0f} 863 \mathrm{cb} 7 \mathrm{a}$.

15. Hutton E. Audiobooks deserve marketing, too. Publ Wkly. 2005;252(42):66.

16. Italie H. Publishing saw upheaval in 2020, but 'books are resilient. The Associated Press, December 14, 2020. https://apnews.com/article/race-and-ethnicity-publishing-coronavirus-pandemic-bookpublishing-jonathan-karp-9c6cb2f6f9c91f91d4f5ce224378f046.

17. Kozlowski M. Audiobook trends and statistics for 2020. Good e-Reader, June 20, 2020. https:// goodereader.com/blog/audiobooks/audiobook-trends-and-statistics-for-2020.

18. Kelly H. From podcasts to Clubhouse, audio is filling more of our time. For some families, that's a problem. The Washington Post, March 15, 2021. https://www.washingtonpost.com/technology/ 2021/03/15/audio-time-clubhouse-podcasts/.

19. Kilgariff K, Hardstark G. My favorite murder. Podcast. https://myfavoritemurder.com/.

20. Kilgariff K, Hardstark G. Stay sexy and don't get murdered. New York: Macmillan Publishers; 2019.

21. Lamb A. Listeners' Advisory Part 2: Connecting Audiobooks With Today's Readers. Teach Libr. 2018;45(3):62-5.

22. Lewis, Clark. Audio publishers association 2011 annual sales survey. Audio Publishers Association, November 2011.

23. Levitz P. The future of publishing. Class discussion at Pace University, Zoom, January 27, 2021.

24. Moon M. Waze adds Audible to its built-in audio player. Yahoo! News, Verizon Media, February 11, 2021. https://news.yahoo.com/waze-audible-102500904.html.

25. Nawotka, Ed. Publishing industry insiders share insights into opportunities, challenges ahead. Publishers Weekly, Publishers Weekly, April 6, 2021. https://www.publishersweekly.com/pw/by-topic/ industry-news/publisher-news/article/86010-publishing-industry-insiders-share-insights-into-oppor tunities-challenges-ahead.html.

26. Pengelly M. 'We cannot survive': New York's Strand bookstore appeals for help.' The Guardian. Guardian News and Media Limited, October 24, 2020. https://www.theguardian.com/us-news/2020/ oct/24/the-strand-bookstore-new-york-plea-for-help.

27. Polson E. 10 intersections between podcasts, audiobooks, and storytelling at large. BookRiot. Riot New Media Group, August 2, 2019. https://bookriot.com/podcasts-audiobooks-storytelling/.

28. Roche MB. Personal interview. By the author. March 5, 2021.

29. Rubery M. The untold story of the talking book. Cambridge: Harvard University Press; 2016.

30. Sackton L. How audiobooks are getting me through COVID-19. BookRiot. Riot New Media Group, April 7, 2020. https://bookriot.com/how-audiobooks-are-getting-me-through-covid-19/.

31. Soares J. 2010 book and e-book sales data for the United States. Productive Writers, February 16, 2011. https://productivewriters.com/2011/02/16/book-e-book-sales-data-united-states-2010/.

32. Stewart D, Casey M, Wigginton C. The ears have it: the rise of audiobooks and podcasting. Deloitte Insights. Deloitte, December 9, 2019. https://www2.deloitte.com/us/en/insights/industry/techn ology/technology-media-and-telecom-predictions/2020/rise-of-audiobooks-podcast-industry.html? id=us:2el:3dp:wsjspon:awa:WSJCMO:2020:WSJFY20.

33. Vasishta J. The power of audiobooks helped me kick my COVID loneliness. Newsday, February 18, 2021. https://www.newsday.com/opinion/coronavirus/covid-19-pandemic-coronavirus-isolationaudiobooks-stories-in-my-head-narration-1.50157772.

34. Zable Fisher M. Turn up the volume on audiobooks. Next Avenue, January 7, 2021. https://www. nextavenue.org/tune-into-audiobooks/.

Publisher's Note Springer Nature remains neutral with regard to jurisdictional claims in published maps and institutional affiliations. 